\title{
Service delivery: subspecialisation, emergencies, sharps injuries, personality traits and the ENT surgeon
}

There is a distinct flavour of psychology, organisational aspects of service delivery and what could be termed 'generalist interest' in this month's issue of The Journal of Laryngology \& Otology. This allows us to take a broad perspective, and complements the more esoteric subject matter on offer in a journal such as ours. These generalist topics are too often neglected in our Continuing Professional Development as we strive to tick the boxes for revalidation in the specifics of our daily practice.

Emergency cover in peripheral and large city ENT units continues to tax National Health Service trusts and rota organisers within departments and hospital groupings. ENT-UK has already addressed the matter of paediatric airway emergencies by providing tailored tuition, but is this just the tip of an iceberg of mismatched demand and skill mix? An analysis of the tension between subspecialisation and safe, effective emergency care won the 2014 ENT-UK undergraduate essay prize and is presented as a review, with several ideas for improving the current situation. ${ }^{1}$ One such idea is a well set up emergency clinic, which was covered in a recent article in relation to the importance of senior cover in such clinics. ${ }^{2}$ Bannister and colleagues' article from Scotland demonstrates an increase in emergency presentations of head and neck cancer cases, particularly oropharyngeal cancer, which is not easily explained at present. ${ }^{3}$ There is certainly room for improvement in generating confidence among junior doctors in basic emergency skills in ENT, particularly in the accident and emergency department. ${ }^{4}$

There is much folklore about what makes someone enter a particular specialty, the caricature cardiac surgeon being somewhat different from the caricature psychiatrist. So where does the ENT surgeon fit in? A study by Vijendren et al. found a significantly higher proportion of type A personalities in ENT specialty trainees compared to foundation doctors, which would be true of surgeons in general; this personality type predisposes one to burnout in later career. ${ }^{5}$ Future studies on subspecialties of ENT, in a similar vein, might provide some interesting insights, but I doubt if many of us would be surprised by the findings! Whether personality type is responsible for a disappointingly low (one-third) reporting rate for sharps injuries in a paper by the same author ${ }^{6}$ is debatable, but it seems that there are plenty of other reasons on offer to explain this, such as cumbersome reporting procedures.

Incidental findings on radiology are a part of daily life in otolaryngology, and it is interesting to see a cohort of head and neck cancer patients followed up whose computed tomography (CT) findings showed pulmonary nodules, which is a problem shared by all specialties in which thoracic CT is requested regularly. Zammit-Maempel and coauthors found that only 7.4 per cent of benign looking nodules went on to become malignant, but that malignant nodules were more common in patients presenting with recurrent cancer, compared to those at initial diagnosis. ${ }^{7}$

The review article by Stobbs et al., which clarifies what is and what is not known about e-cigarettes, is timely. ${ }^{8}$ The drive to achieve smoking cessation in our cancer patients is exemplified by a recent article in The Journal ${ }^{9}$ this showed that laryngeal cancer cases are not much helped by e-cigarettes, which is disappointing. The outcome of paying patients to quit is also disappointing, as reported in a US study recently published in The Journal. ${ }^{10}$

\section{EDWARD FISHER ROBIN YOUNGS \\ MUSHEER HUSSAIN JONATHAN FISHMAN Senior Editors}

References

1 Rouhani MJ. In the face of increasing subspecialisation, how does the specialty ensure that the management of ENT emergencies is timely, appropriate and safe? J Laryngol Otol 2016;130: 516-20

2 Mirza A, McClelland L, Daniel M, Jones N. The ENT emergency clinic: does senior input matter? J Laryngol Otol 2013;127;15-19

3 Bannister M, Vallamkondu V, Ah-See KW. Emergency presentations of head and neck cancer: a modern perspective. J Laryngol Otol 2016;130:571-4

4 Whitcroft KL, Moss B, McRae A. ENT and airways in the emergency department: national survey of junior doctors' knowledge and skills. J Laryngol Otol 2016;130:183-9

5 Vijendren A, Yung M, Sanchez J, Shiralkar U, Weigel L. An exploratory investigation of personality types attracted to ENT. J Laryngol Otol 2016;130:587-95

6 Vijendren A, Sanchez J, Yung M. Incidence and reporting of sharps injuries amongst ENT surgeons. J Laryngol Otol 2016; 130:581-6

7 Zammit-Maempel I, Kurien R, Paleri V. Outcomes of synchronous pulmonary nodules detected on computed tomography in head and neck cancer patients: 12-year retrospective review of a consecutive cohort. J Laryngol Otol 2016;130:575-80

8 Stobbs N, Lillis A, Kumar N. E-cigarettes in ENT: what do we need to know? J Laryngol Otol 2016;130:512-15

9 Narwani V, Harries M. Treatment modality: a predictor of continued tobacco use after treatment in patients with laryngeal cancer. J Laryngol Otol 2014;128:153-8

10 Ghosh A, Philiponis G, Bewley A, Ransome ER, Mirza N. You can't pay me to quit: the failure of financial incentives for smoking cessation in head and neck cancer patients. J Laryngol Otol 2016;130:278-83 